\title{
Therapeutic potential of a novel semi-synthetic-sulfated-polysaccharide to suppress inflammatory mediators in $P$. gingivalis LPS stimulated human monocytes/macrophages
}

\author{
Ying $\mathrm{Gu}^{1^{*}}$ (D), Veena Raja ${ }^{2}$, Hsi-Ming Lee ${ }^{2}$, Houlin Hong ${ }^{3}$, Glenn Prestwich ${ }^{4,5}$ and Maria E. Ryan ${ }^{6}$
}

\begin{abstract}
Background: Chronic periodontitis is associated with an increased risk for systemic conditions such as cardiovascular disease, diabetes, and osteoporosis. During chronic periodontitis, endotoxin (lipopolysaccharide, LPS) produced by $P$. gingivalis provokes monocyte accumulation and differentiation into macrophages and increased secretion of proinflammatory cytokines and matrix metalloproteases (MMPs). While normal levels of MMPs are important in cellular function, increased levels of cytokines and MMPs can cause connective tissue destruction.

Results: In the current study, we investigated the therapeutic capability of a novel semi-synthetic sulfated polysaccharide (SAGE) on the production of cytokines and MMPs by cultured human mononuclear cells and macrophages stimulated with endotoxin LPS produced by P. gingivalis, a periodontally-relevant cell culture model. Our research demonstrated SAGE inhibited the LPS induced synthesis of inflammatory mediators including TNF-a, IL-1 $\beta, P G E_{2}$, and MMP-9 in this periodontal-relevant cell culture model. In addition, TLR-2 and TLR-4 levels were also reduced with the SAGE treatment.

Conclusions: The therapeutic potential of this novel semi-synthetic sulfated polysaccharide compound may help to prevent tissue damage and bone loss in patients with periodontal disease or other inflammatory diseases.
\end{abstract}

Keywords: Semi-synthetic-sulfated-polysaccharide, Inflammation, Cytokines, Matrix metalloproteinases (MMPs), Periodontitis

\section{Background}

Periodontal disease is the most prevalent chronic inflammatory diseases characterized by recurrent bacterial infection followed by immune responses derived from host which often progresses into connective tissue breakdown

\footnotetext{
* Correspondence: ying.gu@stonybrook.edu

'Departments of General Dentistry, School of Dental Medicine, Stony Brook University, Stony Brook, NY 11794, USA

Full list of author information is available at the end of the article
}

and alveolar bone loss [1]. During the pathogenesis of periodontitis, anaerobic gram-negative periodontalassociated pathogens (e.g., P. gingivalis, T.forsythia) and the lipopolysaccharide (LPS, endotoxin) in their cell walls stimulate the innate and adaptive immune responses in periodontal tissues [2]. LPS and other virulence factors stimulate the host immune-inflammatory response by binding to Toll-like receptors 2 (TLR-2) and 4 (TLR-4). Both TLR-2 and TLR-4 are membrane

C C The Author(s). 2021 Open Access This article is licensed under a Creative Commons Attribution 4.0 International License, which permits use, sharing, adaptation, distribution and reproduction in any medium or format, as long as you give appropriate credit to the original author(s) and the source, provide a link to the Creative Commons licence, and indicate if changes were made. The images or other third party material in this article are included in the article's Creative Commons licence, unless indicated otherwise in a credit line to the material. If material is not included in the article's Creative Commons licence and your intended use is not permitted by statutory regulation or exceeds the permitted use, you will need to obtain permission directly from the copyright holder. To view a copy of this licence, visit http://creativecommons.org/licenses/by/4.0/ The Creative Commons Public Domain Dedication waiver (http://creativecommons.org/publicdomain/zero/1.0/) applies to the data made available in this article, unless otherwise stated in a credit line to the data. 
proteins, express excessively in peripheral blood leukocytes such as neutrophils and monocytes. TLR-4 is most well-known for recognizing LPS during periodontal inflammation, and play a fundamental role in pathogen recognition and activation of innate immunity via stimulation of NF-kB [3]. This results in local accumulation of inflammatory cells such as neutrophils and monocytes/ macrophages and generate elevated levels of cytokines and other proinflammatory mediators such as the prostaglandins. These mediators exert autocrine or paracrine activities by upregulating the expression of matrix metalloproteinase (MMP) expression and in turn its activity contributes to the destruction and loss of periodontal connective tissue [4].

A family of sulfated and metabolically stabilized anionic polysaccharide derivatives known as semi-synthetic glycosaminoglycan ethers (SAGEs) have been developed and their therapeutic potential to treat chronic inflammatory diseases such as periodontitis have been evaluated [5]. SAGE is synthesized from sulfating and alkylation of nonanimal derived hyaluronic acid (HA), an immunoneutral skin polysaccharide consisting of long polymers of the disaccharide $\mathrm{N}$-acetylglucosamine (GlcNAc) and glucuronic acid (GlcA) linked GlcNacb1-3GlcAb1-4 in repeating units along the chain. A representative SAGE structure is illustrated in (Fig. 1) which was produced from $53 \mathrm{kDa}$ $\mathrm{HA}$ and had a final molecular weight of $5.5 \mathrm{kDa}$.

It has been shown that SAGE exhibits substantial antiinflammatory activities at nanomolar concentrations, including inhibition of cationic PMN proteases, inhibition of the leukocyte adhesion receptor P-selectin, and inhibition of the interaction of the receptor for advanced glycation end-products (RAGE) with its disparate ligands [6]. Additionally, SAGE effectively reduce inflammation in an animal model of rosacea by binding to cationic cathelicidin peptide LL-37 [7]. Since chronic inflammatory condition such as periodontitis is characterized by a local accumulation of leukocytes, predominantly (70\%) mononuclear cells, in the present study, we investigated the effect of a novel semi-synthetic sulfated polysaccharide (SAGE) on the production of cytokines and MMPs

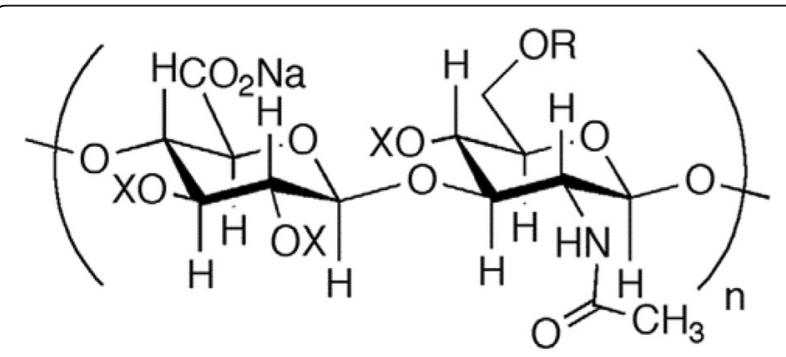

$$
\mathbf{X}=\text { sulfate or } \mathrm{H} ; \mathbf{R}=\text { alkyl }
$$

Fig. 1 Structure of semi-synthetic glycosaminoglycan ethers (SAGES) by cultured human mononuclear cells/macrophages stimulated with endotoxin (lipopolysaccharide, LPS) produced by $P$. gingivalis, a periodontally-relevant cell culture model.

\section{Results \\ Cell culture studies - human peripheral blood mononuclear cells (PBMC)}

As shown in Fig. 2, monocytes from human peripheral blood produced minimal levels of IL-1 $\beta(<25 \mathrm{pg} / \mathrm{ml})$. When LPS $(50 \mathrm{ng} / \mathrm{mL})$ was added to the culture, monocytes secreted $189 \mathrm{pg} / \mathrm{mL}$ of IL- $1 \beta$ with $99.9 \%$ significant increase $(P<0.05)$. SAGE at different concentrations $(25 \mu \mathrm{g} /$ $\mathrm{ml}$ to $200 \mu \mathrm{g} / \mathrm{ml})$ significantly reduced IL-1 $\beta$ levels $(P<$ 0.05 ) by $35 \%$ approximately when stimulated with LPS.

Similarly, monocytes secreted $84 \mathrm{pg} / \mathrm{mL}$ of TNF $-\alpha$ with $93 \%$ significant $(p<0.05)$ increase when LPS was added to the culture, SAGE at different concentrations significantly reduced TNF - $\alpha$ levels $(P<0.05)$ by $35 \%$ approximately when stimulated with LPS (Fig. 3 ).

$\mathrm{PGE}_{2}$ and IL-6 levels were evaluated as well. Both inflammatory mediators were significantly increased when monocytes were stimulated with LPS. $\mathrm{PGE}_{2}$ level was increased from $0.47 \mathrm{ng} / \mathrm{mL}$ to $0.9 \mathrm{ng} / \mathrm{mL}$, and IL-6 level was increased from $4 \mathrm{pg} / \mathrm{mL}$ to $1812 \mathrm{pg} / \mathrm{mL}$. However, SAGE at different concentrations did not significantly reduce these elevated levels.

\section{Cell culture studies - human macrophage}

In separate experiments, the monocytes were allowed to mature for 7 days into macrophages and cytokines levels in the CM were assessed by ELISA. Macrophages secreted $46 \mathrm{pg} / \mathrm{mL}$ of IL- $1 \beta$ when LPS was added to the culture compared to control cells, a 50\% significant increase. SAGE at different concentrations significantly reduced IL-1 $\beta$ levels $(P<0.05)$ by $60 \%$ approximately when stimulated with LPS (Fig. 4).

Similarly, macrophages alone secreted $27 \mathrm{pg} / \mathrm{mL}$ of TNF- $\alpha$, When LPS was added to the culture, TNF- $\alpha$ level was increased significantly by $70 \%(p<0.05)$. SAGE at final concentration of $200 \mu \mathrm{g} / \mathrm{ml}$ significantly reduced TNF $-\alpha$ levels $(P<0.05)$, and SAGE also reduced TNF- $\alpha$ levels by $20 \%$ approximately with other concentrations when stimulated with LPS (Fig. 5), but was not statistically significant.

In contrast to monocytes, $\mathrm{PGE}_{2}$ level was significantly increased by $170 \%$ when macrophages were stimulated with LPS $(p<0.05)$ and there was significant reduction in $\mathrm{PGE}_{2}$ levels in the presence $200 \mu \mathrm{g} / \mathrm{ml} \mathrm{SAGE}$ and there was approximately $60 \%$ reduction in presence of 25 to $100 \mu \mathrm{g} / \mathrm{ml}$ of SAGE (Fig. 6).

The macrophages stimulated with endotoxin did not lead to significant elevations in IL-6 above un-stimulated 


\section{IL-1 beta levels in human monocytes}

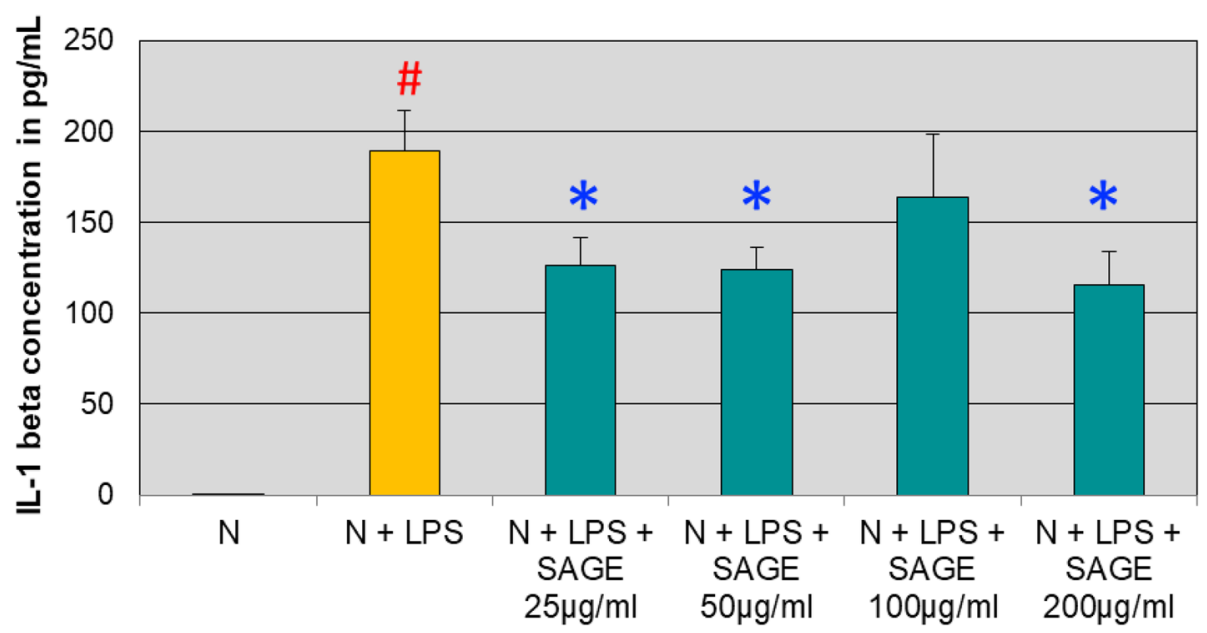

Fig. 2 Inhibition of IL-1 $\beta$ levels by SAGE in human monocytes. Monocytes $\left(1 \times 10^{6}\right.$ cells/well) were cultured in serum-free media $\left(37^{\circ} \mathrm{C}, 5 \% \mathrm{CO}_{2} /\right.$ $95 \% \mathrm{O}_{2} 18 \mathrm{~h}$ ) with LPS (50 ng/mL), SAGE, or vehicle alone. Conditioned medium were analyzed for IL-1 $\beta$ by ELISA. Each value represents the mean of 3 cultures \pm the standard error of the mean (S.E.M.). \#: $p<0.05$ vs normal and *: $P<0.05$ vS LPS

cells and slight reduction of IL-6 levels was seen at 100$200 \mu \mathrm{g} / \mathrm{ml} \mathrm{SAGE}$, but was not statistically significant.

MMP-9 and MMP-2 levels in macrophage CM were also evaluated by gelatin zymography and western blot. When MMP-9 levels were quantified, there was significant increase $(p<0.05)$ in MMP-9 levels in the conditioned media stimulated with LPS. SAGE at different concentrations significantly reduced $(p<0.05)$ MMP-9 levels by $70 \%$ approximately in a dose-dependent manner (Figs. 7 and 8). No significant MMP-2 levels were detected by gelatin zymography.

Both TLR-2 and TLR-4 play essential role in periodontal inflammation. Therefore, to begin to explore the underlying mechanism of SAGE on its inhibitory effects

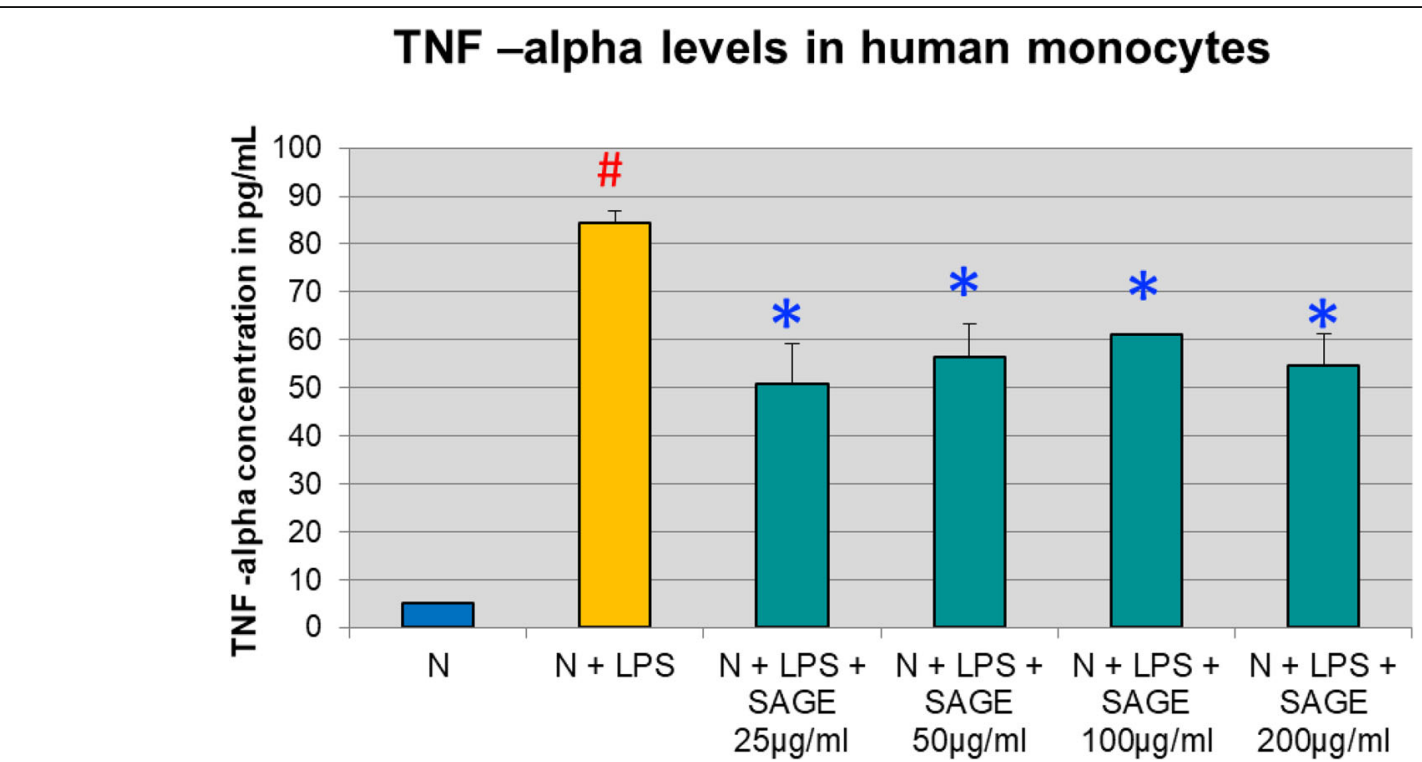

Fig. 3 Inhibition of TNF-a levels by SAGE in human monocytes. Monocytes $\left(1 \times 10^{6}\right.$ cells/well) were cultured in serum-free media $\left(37^{\circ} \mathrm{C}, 5 \% \mathrm{CO}_{2} /\right.$ $95 \% \mathrm{O}_{2} 18 \mathrm{~h}$ ) with LPS (50 ng/mL), SAGE, or vehicle alone. Conditioned medium were analyzed for TNF-a by ELISA. Each value represents the mean of 3 cultures \pm the standard error of the mean (S.E.M.). \#: $p<0.05$ vs normal and *: $P<0.05$ vs LPS 


\section{IL -1 beta levels in human macrophages}

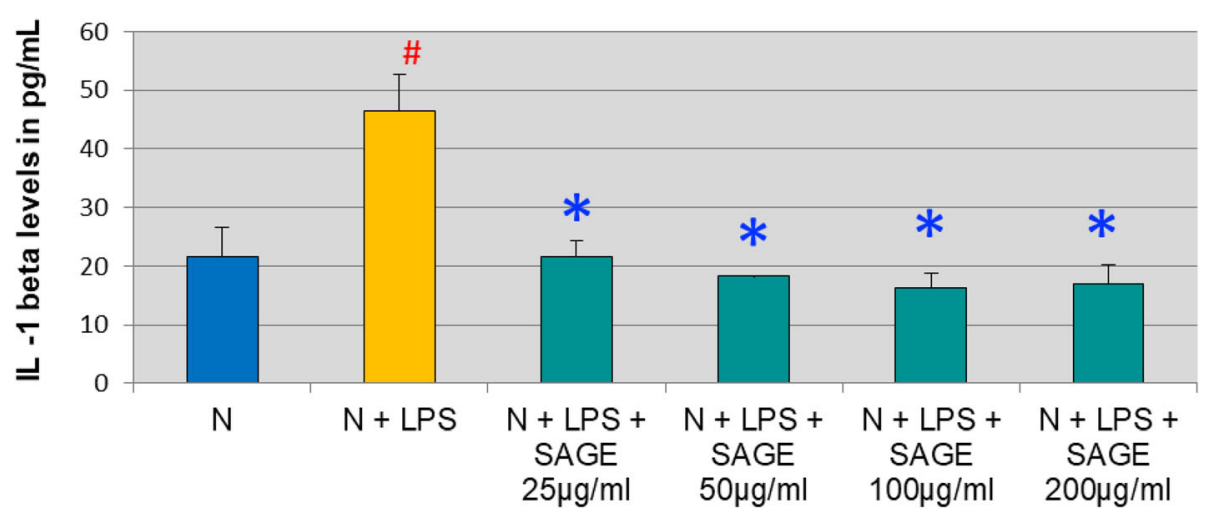

Fig. 4 Inhibition of IL-1 $\beta$ levels by SAGE in human macrophages. Macrophages $\left(1 \times 10^{6}\right.$ cells/well) were cultured in serum-free media $\left(37^{\circ} \mathrm{C}, 5 \%\right.$ $\mathrm{CO}_{2} / 95 \% \mathrm{O}_{2} 18 \mathrm{~h}$ ) with LPS ( $\left.50 \mathrm{ng} / \mathrm{mL}\right)$, SAGE, or vehicle alone. Conditioned medium were analyzed for IL-1 $\beta$ by ELISA. Each value represents the mean of 3 cultures \pm the standard error of the mean (S.E.M.). \#: $p<0.05$ vs normal and *: $P<0.05$ vs LPS

on the inflammatory mediators, the effects of SAGE on TLR-2 and TLR-4 levels in monocyte-derived macrophage culture supernatants were analyzed by Western blotting. Both TLR-2 and TLR-4 were detected. The band density showed $80 \%$ significant increase $(p<0.05)$ of TLR-2 and TLR -4 levels when macrophages were stimulated with LPS and there is $50 \%$ significant decrease $(p<0.05)$ in TLR-2 levels with different concentrations of SAGE when stimulated with LPS. Similar effect was seen with TLR-4 levels where SAGE at different concentrations significantly reduced $(p<0.05)$ TLR-4 levels and there was approximately $80 \%$ reduction (Figs. 9 and 10).

GAPDH levels were used as internal controls and there was no difference in band density in human macrophage supernatants (Fig. 11).

\section{Discussion}

Periodontitis is a chronic inflammatory disease where the host modulatory response plays a critical role in inflammation. Mononuclear phagocytes are attracted to

\section{TNF-alpha levels in human macrophages}

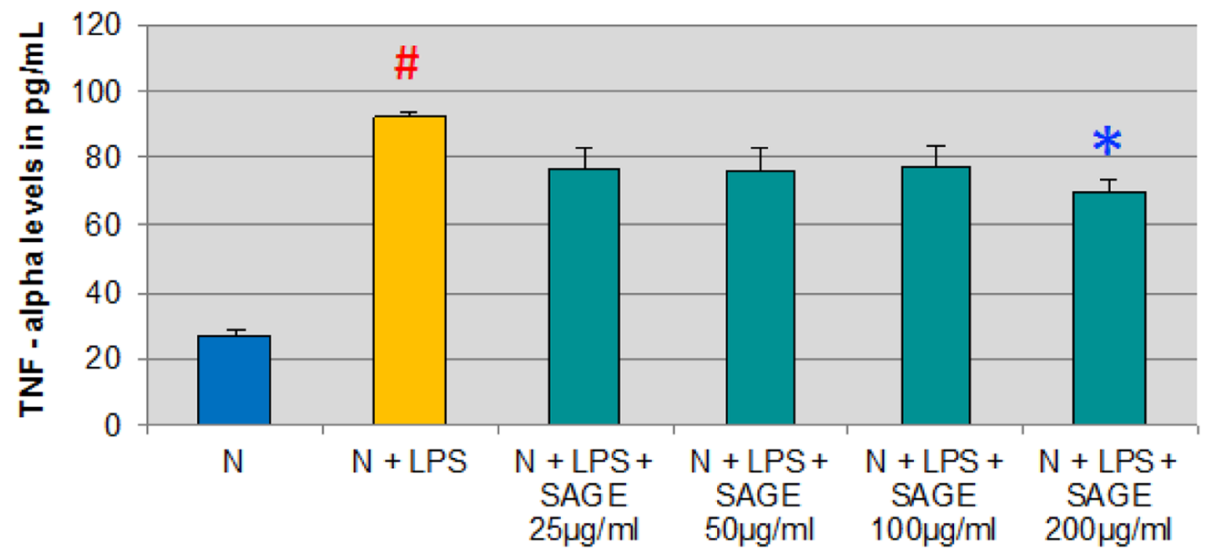

Fig. 5 Inhibition of TNF-a levels by SAGE in human macrophages. Macrophages $\left(1 \times 10^{6}\right.$ cells/well) were cultured in serum-free media $\left(37^{\circ} \mathrm{C}, 5 \%\right.$ $\mathrm{CO}_{2} / 95 \% \mathrm{O}_{2} 18 \mathrm{~h}$ ) with LPS (50 ng/mL), SAGE, or vehicle alone. Conditioned medium were analyzed for TNF-a by ELISA. Each value represents the mean of 3 cultures \pm the standard error of the mean (S.E.M.). \#: $p<0.05$ vs normal and *: $P<0.05$ vs LPS 


\section{$\mathrm{PGE}_{2}$ levels in human macrophages}

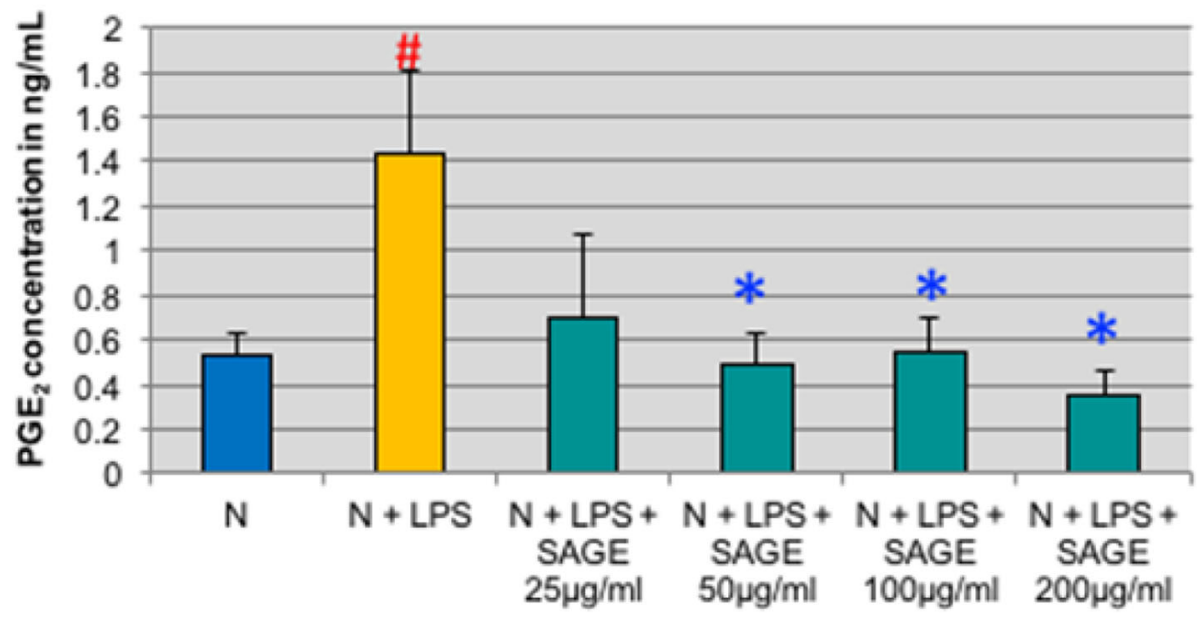

Fig. 6 Inhibition of PGE 2 levels by SAGE in human macrophages. Macrophages $\left(1 \times 10^{6}\right.$ cells/well) were cultured in serum-free media $\left(37^{\circ} \mathrm{C}, 5 \%\right.$ $\mathrm{CO}_{2} / 95 \% \mathrm{O}_{2} 18 \mathrm{~h}$ ) with LPS ( $\left.50 \mathrm{ng} / \mathrm{mL}\right)$, SAGE, or vehicle alone. Conditioned medium were analyzed for PGE 2 by ELISA. Each value represents the mean of 3 cultures \pm the standard error of the mean (S.E.M.). \#: $p<0.05$ vs normal and *: $P<0.05$ vs LPS
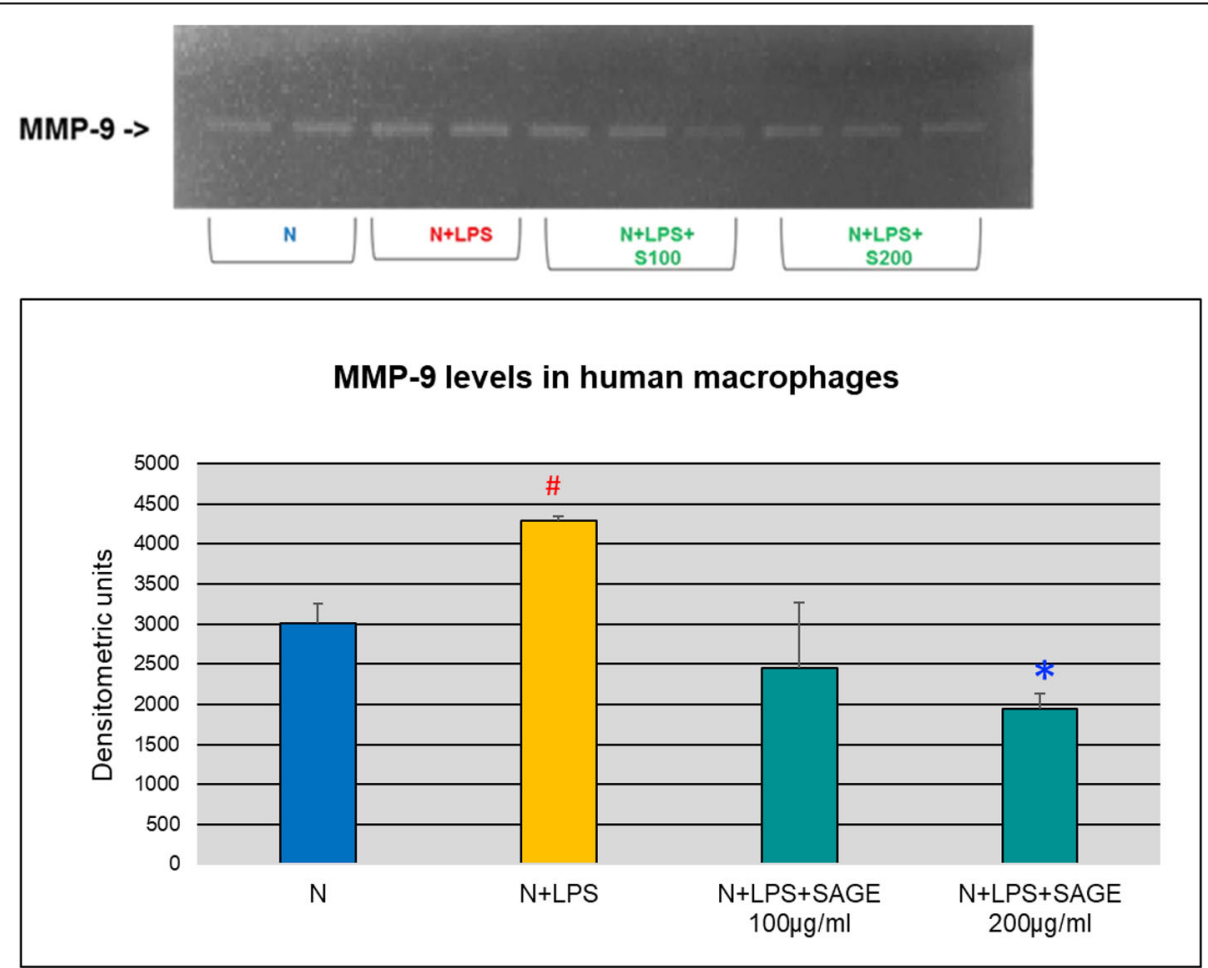

Fig. 7 Inhibition of MMP-9 levels by SAGE in human macrophages (gelatin zymography). Macrophages $\left(1 \times 10^{6}\right.$ cells/well) were cultured in serum-free media $\left(37^{\circ} \mathrm{C}, 5 \% \mathrm{CO}_{2} / 95 \% \mathrm{O}_{2} 18 \mathrm{~h}\right.$ ) with LPS (50 ng/mL), SAGE, or vehicle alone. Conditioned medium were analyzed by gelatin zymography. Levels of MMP-9 and MMP-2 were quantified by measuring band intensity using Image J. Each value represents the mean of 3 cultures \pm the standard error of the mean (S.E.M.). \#: $p<0.05$ vs normal and *: $P<0.05$ vs LPS 


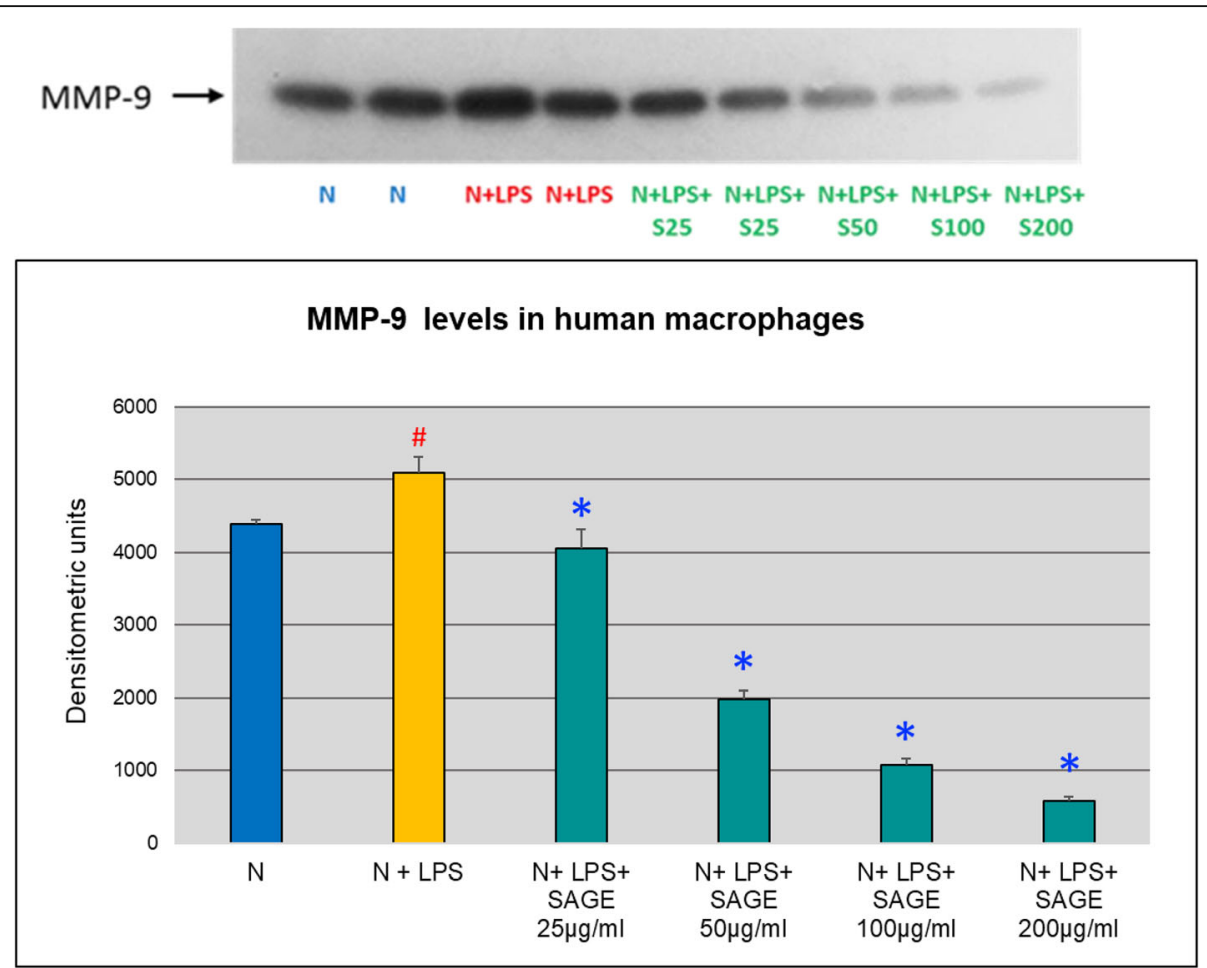

Fig. 8 Inhibition of MMP-9 levels by SAGE in human macrophages (Western blot). Macrophages $\left(1 \times 10^{6}\right.$ cells/well) were cultured in serum-free media $\left(37^{\circ} \mathrm{C}, 5 \% \mathrm{CO}_{2} / 95 \% \mathrm{O}_{2} 18 \mathrm{~h}\right.$ ) with LPS (50 ng/mL), SAGE, or vehicle alone. Conditioned medium were analyzed by Western blot. Levels of MMP-9 and MMP-2 were quantified by measuring band intensity using Image J. Each value represents the mean of 3 cultures \pm the standard error of the mean (S.E.M.). \#: $p<0.05$ vs normal and *: $P<0.05$ vs LPS

the site of inflammation by chemotactic signals which in turn releases proteinases and cytokines resulting in tissue damage. Previous studies showed that SAGE, highly sulfated GAG is anti-inflammatory at nano-molar concentration including blockade of P- and L-selectin, inhibition of PMN derived human neutrophil elastase (HLE) and attenuates LL-37 induced bladder inflammation. In addition, Glycosaminoglycans (GAGs), such as hyaluronic acid, heparin, and more recently synthetic GAGs, have been shown to interfere with bacterial growth. SAGEs are bacteriostatic, potently inhibit CR3, block CR3-mediated $P g$ uptake in human macrophages $[5,8]$. Herein we show that this novel sulfated glysoaminoglycan ether has broad antiinflammatory activity. When SAGE was added to the monocyte derived macrophages in cell cultures at 25$200 \mu \mathrm{g} / \mathrm{ml}$, it attenuated upstream inflammatory signaling receptors, pro-inflammatory cytokines as well as matrix metalloproteinases. Our data in most assays indicated that the maximum inhibition was achieved by the lowest concentration $25 \mu \mathrm{g} / \mathrm{ml}$ applied, the inhibitory effects at higher concentrations of SAGE were plateaued. This observation is taken into consideration when evaluating in vivo doses. The cell cytotoxicity was also evaluated to exclude that the anti-inflammatory effect of SAGE was not the result of cell toxicity (Fig. 12). A MTS assay with a tetrazolium compound was used to assess cell proliferation, cell viability and cytotoxicity. The results showed that SAGE at concentrations from 25 to $200 \mu \mathrm{g} / \mathrm{ml}$ was not toxic to human peripheral blood mononuclear cells (PBMC).

The initial driving force for periodontitis is infection of the gingival tissues with oral bacteria, particularly those of the anaerobic, gram-negative "red complex", primary of which is $P$. gingivalis [9]. This bacterial biofilm is the primary inflammatory stimulus for chronic inflammation, however, the ultimate outcome of the disease is determined by the host response. Recognition of pathogenic bacteria by the host requires mechanisms to mount an appropriate response that can prevent the dissemination of infection. The host immune system detects invading pathogens primarily through pattern-recognition receptors. These receptors recognize pathogen associated molecular patterns (PAMPs) that are typically shared by large groups of microorganisms, i.e. LPS [10]. The Toll-like receptors are members of interleukin-1 super-family of transmembrane receptors that identify pathogen associated molecular patterns [11]. For the recognition and transduction of the lipopolysaccharide signal the transmembrane Toll-like receptor- 4 and 2 present in the mononuclear phagocytes plays a pivotal role. Upon binding of lipopolysaccharide, the Toll-like receptor-4 activates the inflammatory 

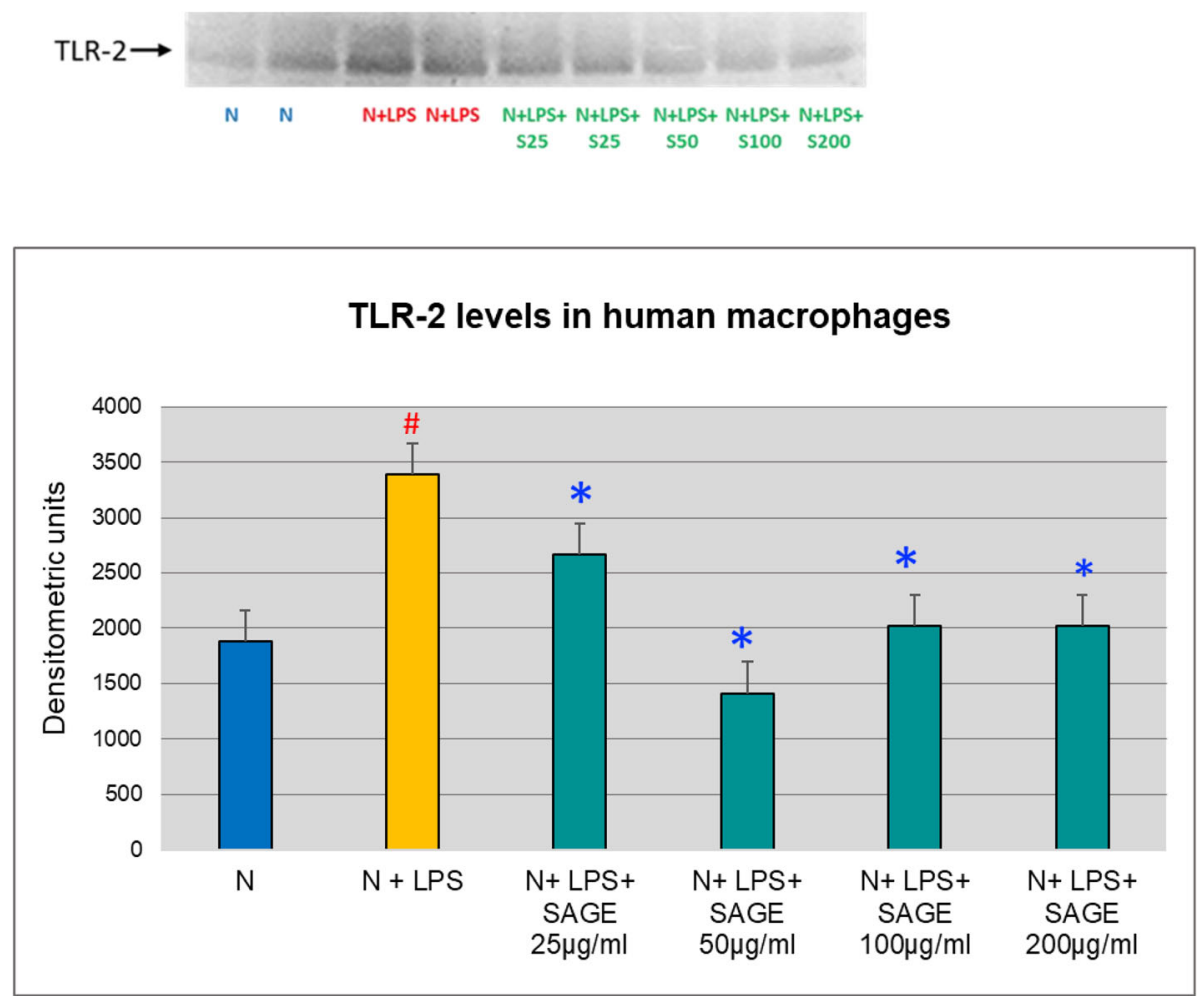

Fig. 9 Inhibition of TLR-2 levels by SAGE in human macrophages (Western blot). Macrophages $\left(1 \times 10^{6}\right.$ cells/well) were cultured in serum-free media $\left(37^{\circ} \mathrm{C}, 5 \% \mathrm{CO}_{2} / 95 \% \mathrm{O}_{2} 18 \mathrm{~h}\right.$ ) with LPS ( $\left.50 \mathrm{ng} / \mathrm{mL}\right)$, SAGE, or vehicle alone. Conditioned medium were analyzed by Western blot. Levels of TLR-2 were quantified by measuring band intensity using Image J. Each value represents the mean of 3 cultures \pm the standard error of the mean (S.E.M.). \#: $p<0.05$ vs normal and *: $P<0.05$ vs LPS.

cascade system ultimately leading to the synthesis and release of pro-inflammatory cytokines and proteinases which are potential stimulators for tissue destructive effects in periodontitis [12]. Our Immunoblotting results showed the expression levels of TLR-2 and TLR- 4 in macrophages were diminished with $25-200 \mu \mathrm{g} / \mathrm{ml}$ of SAGE, which can contribute to the downstream reduction in the levels of pro-inflammatory mediators.

Pro-inflammatory cytokines such as IL- $1 \beta$, TNF- $\alpha$ and IL- 6 are produced by monocytes, and macrophages and play a critical role in the pathogenesis of periodontitis [13-15]. Once these cytokines are released, they stimulate the production of critical enzymes such as MMPs, which are largely responsible for the direct breakdown of connective tissues in chronic inflammatory diseases $[16,17]$. IL-1 $\beta$ and TNF- $\alpha$ and IL- 6 also activate other mediators of inflammation such as cycloxygenase- 2 and 5- lipoxygenase, leading to the production of lipid mediators of inflammation, such as prostaglandins $\left(\mathrm{PGE}_{2}\right)$ and leukotrienes [18]. Inhibition of pro-inflammatory cytokines decreases the loss of connective tissue attachment thereby attenuating periodontitis. SAGE has been found to exhibit anti- inflammatory activities. In this study SAGE effectively reduced the levels of IL-1 $\beta$ and
TNF- $\alpha$ in monocyte significantly whereas there was not much effect on systemic cytokines IL- 6 and PGE 2 . While in cell culture assays with human macrophages, there was dose-dependent decrease in levels of IL-1 $\beta$, TNF- $\alpha$ and $\mathrm{PGE}_{2}$ which in turn reduces the MMP-9 levels thereby inhibiting the host-mediated inflammatory cascade system. SAGE disrupts the events associated with periodontitis in multiple manners, spanning from the early pro- inflammatory TLR signaling to molecular pathways involving pro-inflammatory cytokines and MMPs, and consequently prevents tissue breakdown.

\section{Conclusions}

In conclusion, the findings presented in this paper demonstrated the cell-mediated anti-inflammatory activity of SAGE in the treatment of chronic inflammatory diseases such as periodontal disease, is mediated at least in part through TLR-2 and TLR-4 signaling pathway. The suppression of inflammatory signaling and MMPs can be beneficial to reduce pathologically excessive degradation of the extracellular matrix including connective tissues and alveolar bones. Currently, the anti-inflammatory effect of SAGE in the management of periodontal disease is being investigated in vivo in a 

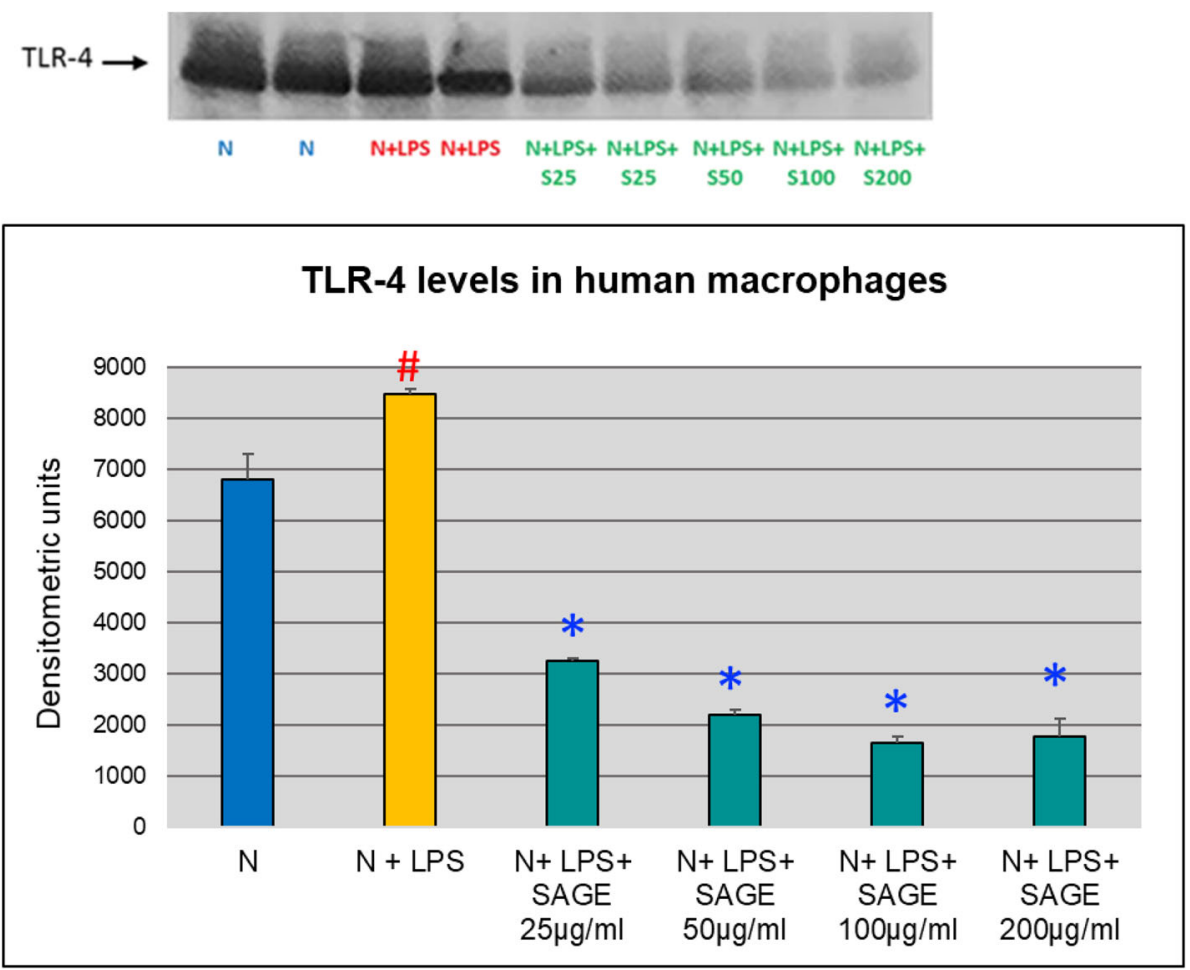

Fig. 10 Inhibition of TLR-4 levels by SAGE in human macrophages (Western blot). Macrophages $\left(1 \times 10^{6}\right.$ cells/well) were cultured in serum-free media $\left(37^{\circ} \mathrm{C}, 5 \% \mathrm{CO}_{2} / 95 \% \mathrm{O}_{2} 18 \mathrm{~h}\right.$ ) with LPS $(50 \mathrm{ng} / \mathrm{mL})$, SAGE, or vehicle alone. Conditioned medium were analyzed by Western blot. Levels of TLR-4 were quantified by measuring band intensity using Image J. Each value represents the mean of 3 cultures \pm the standard error of the mean (S.E.M.). \#: $p<0.05$ vs normal and *: $P<0.05$ vs LPS

diabetic rat model. The results of the in vivo research will be reported in a future article.

\section{Materials and methods Chemical reagents}

All chemical reagents, and LPS from P. gingivalis were purchased from Sigma-Aldrich Co. (St. Louis, MO). Cell culture reagents were purchased from Gibco/Invitrogen Corp. (Carlsbad, CA). SAGE (GM - 1111) was obtained from GlycoMira, LLC (Salt Lake City, UT).

\section{Cell culture assay}

Human peripheral blood mononuclear cells (PBMC) were isolated and purified from Leukocyte Concentrate, which was purchased from Long Island Blood Bank (Melville, NY). The project (2007-6548) was approved for exemption by Stony Brook University Committees on Research Involving Human Subjects (CORIHS). Human PBMC were isolated by density gradient centrifugation as described by us previously [19]. PMBC were cultured in serum-free macrophage media (Invitrogen Corp, Carlsbad, CA) for $18 \mathrm{~h}$. LPS from P. gingivalis $(50 \mathrm{ng} / \mathrm{mL}$ ) or vehicle were added before the incubation.

\section{GAPDH}

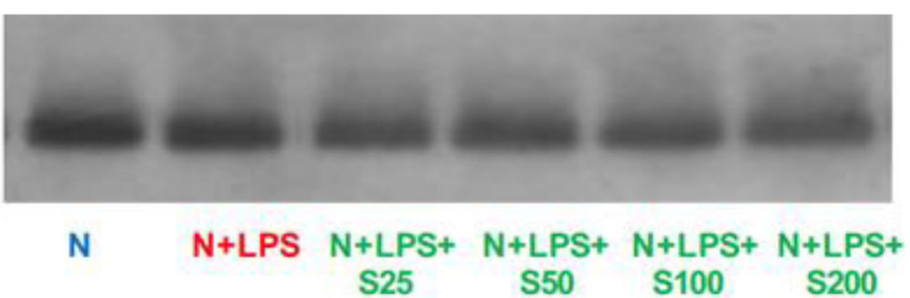

Fig. $11 \mathrm{GAPDH}$ levels in human macrophages. Macrophages $\left(1 \times 10^{6} \mathrm{cells} /\right.$ well) were cultured in serum-free media $\left(37^{\circ} \mathrm{C}, 5 \% \mathrm{CO}_{2} / 95 \% \mathrm{O}_{2} 18 \mathrm{~h}\right)$ with LPS $(50 \mathrm{ng} / \mathrm{mL})$, SAGE, or vehicle alone. Levels of GAPDH in conditioned medium were by Western blot 


\section{Human PBMC Viability Assay}

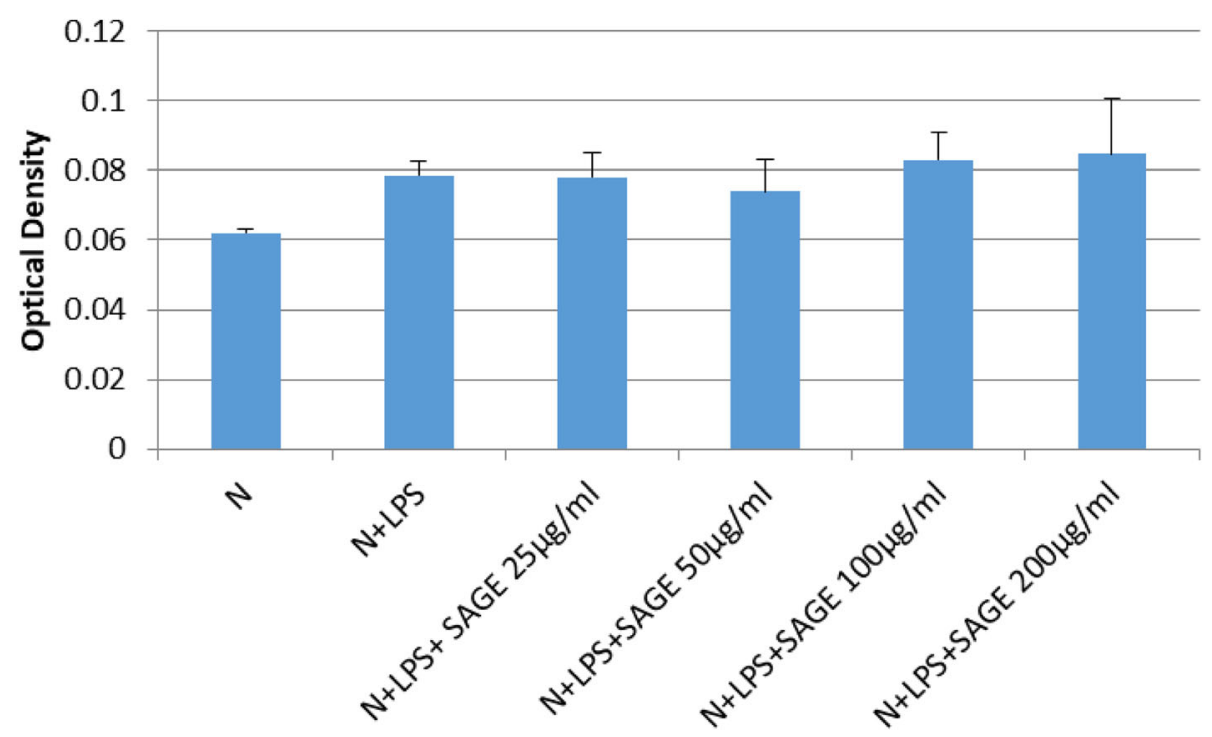

Fig. 12 Human PBMC MTS viability assay. Human PBMC $\left(1 \times 10^{6}\right.$ cells/well) were cultured in serum-free media $\left(37^{\circ} \mathrm{C}, 5 \% \mathrm{CO}_{2} / 95 \% \mathrm{O}_{2} 18 \mathrm{~h}\right)$ with LPS $(50 \mathrm{ng} / \mathrm{mL})$, SAGE, or vehicle alone. MTS tetrazolium compound was added and incubated for $2 \mathrm{~h}$. The formazan dye was quantified by measuring the absorbance at $490 \mathrm{~nm}$. Each value represents the mean of 3 cultures \pm the standard error of the mean (S.E.M.)

SAGE was added at final concentrations of 25 to $200 \mu \mathrm{g} /$ $\mathrm{ml}$. Conditioned media (CM) were analyzed for the cytokines and pro-inflammatory mediators, Tumor necrosis factor - alpha (TNF- $\alpha$ ), Interleukin - 1 beta (IL-1 $\beta$ ), Interleukin - 6 (IL-6), and Prostaglandin $\mathrm{E}_{2} \quad\left(\mathrm{PGE}_{2}\right)$, by enzyme-linked immunosorbent assay (ELISA) as described by us previously [20].

In separate assays, PBMC were cultured for 7 days to allow for maturation to macrophage. Macrophages were then cultured for $18 \mathrm{~h}$ with or without LPS $(50 \mathrm{ng} / \mathrm{mL})$. SAGE at different concentrations were also added to the culture at the beginning of the experiment. The CM were analyzed for 1 . TNF- $\alpha$, IL- $1 \beta$, IL- 6 and PGE $_{2}$ by ELISA; 2. MMPs by gelatin zymography and Western blot; and 3. TLR-2 and TLR-4 expression by Western blot. Gelatin zymography and Western blot assays were described below.

\section{MTS cell viability assay}

Human PBMC $\left(1 \times 10^{6}\right.$ cells/well $)$ were cultured in serum-free media $\left(37^{\circ} \mathrm{C}, 5 \% \mathrm{CO}_{2} / 95 \% \mathrm{O}_{2} 18 \mathrm{~h}\right)$ with LPS (50 ng/mL), SAGE, or vehicle alone. The CellTiter $96^{\circ}$ AQueous One Solution Reagent contains a tetrazolium compound was added to the culture and incubated for 2 h. The formazan product was quantified by measuring the absorbance at $490 \mathrm{~nm}$. The MTS assay kit was purchased from Promega Corp. (Madison, WI).

\section{ELISA assay}

Cell culture CM collected from the above assays were analyzed for pro-inflammatory cytokines: TNF- $\alpha$, IL-1 $\beta$, IL-6 and PGE 2 . ELISA kits for TNF- $\alpha$, IL-1 $\beta$, IL-6 and $\mathrm{PGE}_{2}$, were purchased from R\&D Systems, Inc. (Minneapolis, MN). ELISA assays were performed and followed manufacturer's protocol.

\section{Gelatin Zymography}

The gelatin zymography system were purchased from Invitrogen Corp. (Carlsbad, CA). MMP-2 and MMP-9 standards were purchased from $R \& D$ Systems, Inc. (Minneapolis, MN). CM collected from the above cell culture assays were analyzed by gelatin zymography as described by us previously [20]. SDS-PAGE gels with 1 $\mathrm{mg} / \mathrm{ml}$ gelatin were used. After electrophoresis, the gels were washed with $2.5 \%$ Triton $\mathrm{X}-100$ and incubated at $37^{\circ} \mathrm{C}$ overnight in calcium assay buffer (40 mM Tris/ $\mathrm{HCl}, 200 \mathrm{mM} \mathrm{NaCl}, 10 \mathrm{mM} \mathrm{CaCl} 2, \mathrm{pH}$ 7.5), then stained with Coomassie Brilliant Blue R-250. As described by us earlier [19], clear zones of lysis against a blue background indicate gelatinolytic activity and levels of MMP9 and MMP-2 were quantified by measuring band intensity using Image J analysis software [21].

\section{Western blot analysis}

CM collected from human macrophage cell culture were analyzed for TLR-2, TLR-4, and MMP-9 by Western 
blot analysis. All Western blot procedures were performed as described by us previously [22]. Prestained molecular weight markers were purchased from Bio-Rad Laboratories, Inc. (Hercules, CA). CM samples were electrophoresed on SDS-PAGE (8\% separating and 4\% stacking gels). Proteins were transferred to nitrocellulose membranes, and incubated with primary antibodies (TLR-2: Abcam, Cambridge, MA; TLR-4: Life Technologies, Carlsbad, CA; MMP-9: Cell Signaling Technology, Danvers, MA). Excess primary antibodies were removed before incubation with the secondary antibodies conjugated to horseradish peroxidase (Goat anti-rabbit antibodies, Cell Signaling Co., Danvers, MA). Detection of the protein bands was carried out by scanning the membranes with Invitrogen ${ }^{\mathrm{Tm}}$ iBright $^{\mathrm{Tm}}$ FL1000 Western Blot Imaging Systems (Thermo Fisher Scientific, Inc., USA) and quantified by measuring band intensity using Image J analysis software. Glyceraldehyde-3-phosphate dehydrogenase (GAPDH) was used as an internal control.

\section{Statistical analysis}

Cytokine, MMP and receptor levels between groups were analyzed by analysis of variance (ANOVA), with $P$ $\leq 0.05$ taken as statistically significant. Normal versus LPS is represented by \#; LPS versus SAGE treatment is represented by *.

\section{Acknowledgements}

Authors would like to thank Justin Savage (GlycoMira Therapeutics, Inc.), Abby Pulsipher (GlycoMira Therapeutics, Inc.), and Won Yong Lee (GlycoMira Therapeutics, Inc.) for providing SAGE and its manufacturing information.

\section{Authors' contributions}

$Y G, V R$, and $H L$ performed experiments, $Y G, V R, H L, H H$, and $M R$ analyzed and interpreted the data. GP provided SAGE for the study. All authors contributed in writing the manuscript. All authors read and approved the final manuscript.

\section{Funding}

This study was supported by GlycoMira Therapeutics, Inc., and a grant from $\mathrm{NIH/NIDCR-1R43DE02216-01.}$

\section{Availability of data and materials}

The data generated and/or analysed during the current study are available from the corresponding author on reasonable request with the permission from GlycoMira Therapeutics, Inc.

\section{Declarations}

Ethics approval and consent to participate Not applicable.

\section{Consent for publication}

Not applicable.

\section{Competing interests}

GP is CSO and holds equity in GlycoMira Therapeutics. YG, VR, HL, HH, and MR declare that they have no competing interests.

\section{Author details}

'Departments of General Dentistry, School of Dental Medicine, Stony Brook University, Stony Brook, NY 11794, USA. ${ }^{2}$ Department of Oral Biology and Pathology, School of Dental Medicine, Stony Brook University, Stony Brook,
NY 11794, USA. ${ }^{3}$ Program in Public Health, Stony Brook Medicine, Stony Brook University, Stony Brook, NY 11794, USA. ${ }^{4}$ Department of Medicinal Chemistry, The University of Utah, Salt Lake City, UT 84112, USA. ${ }^{5}$ Health Sciences Spokane, Washington State University Health Sciences, Spokane, WA 99202, USA. ${ }^{6}$ Colgate Palmolive Company, Piscataway, NJ 08854, USA

Received: 17 November 2020 Accepted: 6 August 2021

Published online: 04 September 2021

\section{References}

1. Ryan ME. Host modulation: conceptualization to clinical trials and integration into clinical practice. J Calif Dent Assoc. 2002;30:285-8 290-5.

2. Van Dyke TE, Van Winkelhoff AJ. Infection and inflammatory mechanisms. J Clin Periodontol. 2013;40(Suppl 14):S1-7.

3. Mogensen TH. Pathogen recognition and inflammatory signaling in innate immune defenses. Clin Microbiol Rev. 2009;22(2):240-73.

4. Gu Y, Ryan ME. Overview of periodontal diseases: causes, pathogenesis, and characteristics. In: Williams R, Genco R, editors. Periodontal diseases and overall health: a clinician's guide. Yardley: Professional Audience Communications: 2009. p. 5-23.

5. Savage J, Pulsipher A, Rao NV, et al. A modified glycosaminoglycan, GM0111, inhibits molecular signaling involved in periodontitis. PLoS One. 2016; 11(6):e0157310.

6. Ryan ME, Raja V, Sussman SK. Periodontitis and diabetes mellitus: a complex relationship. In: Craig RG, Kamer AR, editors. . Berlin Heidelberg: Springer; 2016. p. 19-37.

7. Zhang J, Xu X, Rao NV, et al. Novel sulfated polysaccharides disrupt cathelicidins, inhibit RAGE and reduce cutaneous inflammation in a mouse model of rosacea. PLoS One. 2011;6(2):e16658.

8. Oottamasathien S, Jia W, Mccoard L, et al. A murine model of inflammatory bladder disease: cathelicidin peptide induced bladder inflammation and treatment with sulfated polysaccharides. J Urol. 2011;186(40):1684-92.

9. Golub LM, Evans RT, McNamara TF, Lee HM, Ramamurthy NS. Nonantimicrobial tetracycline inhibits gingival matrix metalloproteinases in Porphyromonas gingivalis-induced periodontitis in rats. Annals NY Acad Sci. 1994;732:96-111.

10. Hoffmann JA, Kafatos FC, Janeway CA, Ezekowitz RA. Phylogenetic perspectives in innate immunity. Science. 1999;284:1313-8.

11. Takeda K, Akira S. Toll receptors and pathogen resistance. Cell Microbiol. 2003;5:143-53.

12. Graves DT, Jiang Y, Genco C. Periodontal disease: bacterial virulence factors, host response and impact on systemic health. Curr Opin Infect Dis. 2000;13: 227-32.

13. Lee HJ, Kang IK, Chung CP, Choi SM. The subgingival microflora and gingival crevicular fluid cytokines in refractory periodontitis. J Clin Periodontol. 1995:22:885-90.

14. Tsai $Y$, Ho Y, Chen C. Levels of interleukin-Iß and interleukin-8 in gingival crevicular fluids in adult periodontitis. J Periodontol. 1995:66:852-9.

15. Leng SX, Elias JA. Interleukin-11 inhibits macrophage interleukin-12 production. J Immunol. 1997:159:2161-8.

16. Martel-Pelletier J, Raynauld JP, Mineau F, et al. Levels of serum biomarkers from a two-year multicentre trial are associated with treatment response on knee osteoarthritis cartilage loss as assessed by magnetic resonance imaging: an exploratory study. Arthritis Res Ther. 2017;19:169. https://doi. org/10.1186/s13075-017-1377-y.

17. Largo R, Alvarez-Soria MA, Díez-Ortego I, et al. Glucosamine inhibits IL- 1 $\beta$ induced NFKB activation in human osteoarthritic chondrocytes. Osteoarthr Cartil. 2003;11:290-8

18. Page R. The pathobiology of periodontal diseases may affect systemic diseases: inversion of a paradigm. Ann Periodontol. 1998;3:108-20.

19. Liao G, Simon SR. Temporal down-regulation of FcyRIII expression and Fcy receptor-mediated phagocytosis in human monocyte-derived macrophages induced by TNF- $a$ and IL-1 $\beta$. J Leukoc Biol. 1994;55:702-10.

20. Gu Y, Lee HM, Napolitano N, Clemens M, Sorsa T, Zhang Y, et al. 4methoxycarbonyl curcumin: a novel inhibitor of inflammatory mediators for periodontitis and other diseases. Mediat Inflamm. 2013. https://doi.org/10.11 55/2013/329740.

21. Lee HM, Ciancio SG, Tuter G, Ryan ME, Golub LM. Sub-antimicrobial dose doxycycline efficacy as a matrix metalloproteinase inhibitor in chronic periodontitis patients is enhanced when combined with an NSAID. J Periodontol. 2004;75:453-63. 
22. Deng J, Golub LM, Lee HM, Lin M, Bhatt H, Hong H, et al. Chemicallymodified Curcumin 2.24: a novel systemic therapy for natural periodontitis in dogs. J. Exp Pharmacol. 2020;12:47-60.

\section{Publisher's Note}

Springer Nature remains neutral with regard to jurisdictional claims in published maps and institutional affiliations.

Ready to submit your research? Choose BMC and benefit from:

- fast, convenient online submission

- thorough peer review by experienced researchers in your field

- rapid publication on acceptance

- support for research data, including large and complex data types

- gold Open Access which fosters wider collaboration and increased citations

- maximum visibility for your research: over $100 \mathrm{M}$ website views per year

At $\mathrm{BMC}$, research is always in progress. 